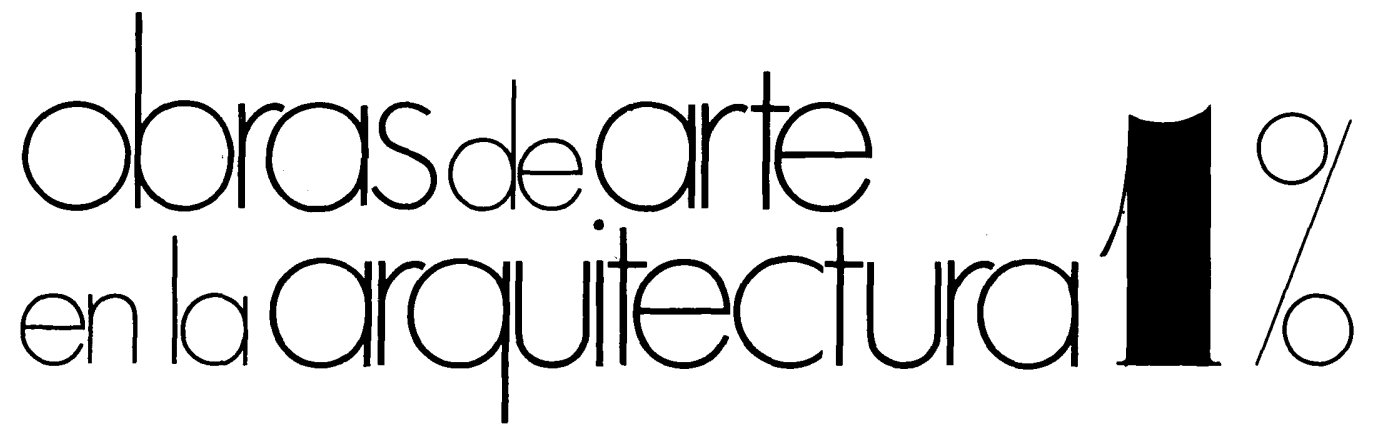

SINOPSIS

Philippe Bayonne, arquitecto

$177-1$

Muchas son las obras de arte debidas a la feliz idea instaurada por el Ministerio de Educación, de consagrar un crédito de un 1 por 100 sobre el costo de construcción, para realizar decoraciones monumentales integradas en todos los edificios escolares y universitarios financiados por el Estado.

Se podrian resumir en tres los fines de este proyecto:

—. ayudar a los artistas a vivir de su obra;

- poner al individuo en contacto con el arte desde sus primeros años; e

- integrar las artes en la arquitectura.

Los resultados conseguidos han sido tan alentadores que, posteriormente, otros ministerios, e incluso algunos municipios, han contribuido de alguna manera al desarrollo de la idea.

Philippe Bayonne ha intervenido frecuentemente en este tipo de realizaciones. El con su obra, y sus colaboradores, quedan reseñados en este trabajo.

La idea de asignar un crédito especial para la realización de decoraciones monumentales en las grandes construcciones del Estado viene desde la época del Frente Popular y había sido ya objeto de dos proyectos de Ley. El objetivo que se. perseguía era esencialmente el de proporcionar trabajo a los artistas en la línea de colocar el arte contemporáneo al alcance de la mayor cantidad de público.

No obstante, hubo que esperar hasta mayo de 1951 para que el Ministro de Educación firmara un apartado que, aunque llevaba algunas modificaciones a los textos que habian sido originalmente concebidos pero que no habian sido adoptados por la Asamblea Nacional, instituyen la obligación de prever trabajos de decoración integrados en la construcción de todos los edificios escolares y universitarios, constituyendo de esta manera el fundamento de la reglamentación Ilamada del 1 por 100.

El crédito afecta a estos trabajos y se calcula en razón al 1 por 100 del costo de la construcción cuando ésta está financiada únicamente por el Estado, y del 1 por 100 del montante de la subvención acordada a las colectividades locales, cuando éstas llevan la iniciativa y la carga financiera de la construcción, sin que a éstas se les tenga en cuenta su propia participación.

Esta medida perseguía tres objetivos precisos:

$1^{\circ}$ De orden socio-económico al tener como fin el de ayudar a los artistas a vivir de su propia creación.

$2^{\circ}$ De orden pedagógico, buscando poner al individuo en contacto con el arte de hoy desde su más tierna infancia.

$3^{\circ}$ Responder al deseo de integrar estrechamente las artes en la arquitectura y de renovar así una tradición demasiado o'vidada.

Con el curso de los años el proceso seguido para la realización de trabajos del 1 por 100 ha sufrido algunas modificaciones. Si el principio sigue fundamentalmente el mismo, un impulso cada vez mayor se ha puesto en el sentido de que es necesaria la integración del arte en la arquitectura y en su entorno bajo la responsabilidad total del arquitecto que, en su calidad de jefe de obra, debe asegurarse con la colaboración de un artista desde los principios del estudio del proyecto de construcción.

El 1 por 100 permite a los artistas trabajar en líneas muy diversas (escultura, pintura, cerámica, mosáico, tapicería, cerrajería, decoración de suelos, vidrieras, adaptación de espacios, etc.) investigando la integración de elementos visuales en función de un entorno dado. El objetivo no es, desde luego, el de "colocar" una obra, sino intervenir en un 
lugar específico con el fin de establecer un equilibrio orgánico e instituir un recorrido real o imaginario en los ritmos que engranen a la ordenanza de los edificios y a la naturaleza en si.

Paralelamente a la evolución de la construcción - sobre todo con el empleo casi sistemático de procedimientos industriales - hemos conocido una renovación total de la inspiración artística, lo mismo en concepciones de las obras, como en las técnicas empleadas.

Los montantes del 1 por 100 de la Educación representan el crédito más importante que el Estado adjudica a adquisiciones de arte contemporáneo.

En razón del crecimiento demográfico que siguió a la última guerra mundial, el ritmo de construcciones escolares y universitarias han sido excepcionalmente importantes.

Algunas administraciones (Agricultura, Defensa, Equipamiento, Cultura, etc.) han aplicado de una manera más o menos completa un proceso parecido al de Educación.

Algunas municipalidades han llevado, desde luego, una política activa dentro de la intervención artística, complementando las subvenciones del Estado o aplicando una medida similar a la del 1 por 100 .

Para Philippe Bayonne, arquitecto, las investigaciones que se refieren a la realización de trabajos de decoración, llamadas del 1 por 100, evolucionaron a partir de 1970 desde la intervención muy localizada de Yves Frangeul, que proponía una escultura monumental para el C.E.S. de 990 alumnos en Avon, a la integración de las artes en la arquitectura y en el entorno mediante asociaciones desde la situación de anteproyecto con André Stempfel para la ciudad escolar técnica de 1.142 alumnos en la misma localidad, y la escuela maternal del Quai de Jemmapes en el Distrito 10 de Paris, o con Dietrich Mohr para el conjunto destinado al C.E.S. de 696 alumnos en Bessancourt.

Entre estas dos líneas se efectúa el diálogo arquitecto-artista a nivel del estudio de decoración.

Se efectúa así para la imaginación del artista el hecho de crear un decorado completo en función de los edificios ya construidos, en curso de construcción o de proyecto definitivo, pero según una repartición de la zona de influencia.

Este es el caso, por una parte, de las policromias y frescos de Champagne Sur Seine y, por otra parte, de los efectos de agua debidos a Jacques Labyt en este mismo conjunto integrando la arquitectura cuando de la fuente monumental que recoge estas aguas es debida a la asociación del arquitecto con Michel Deverne desde el principio del proyecto.
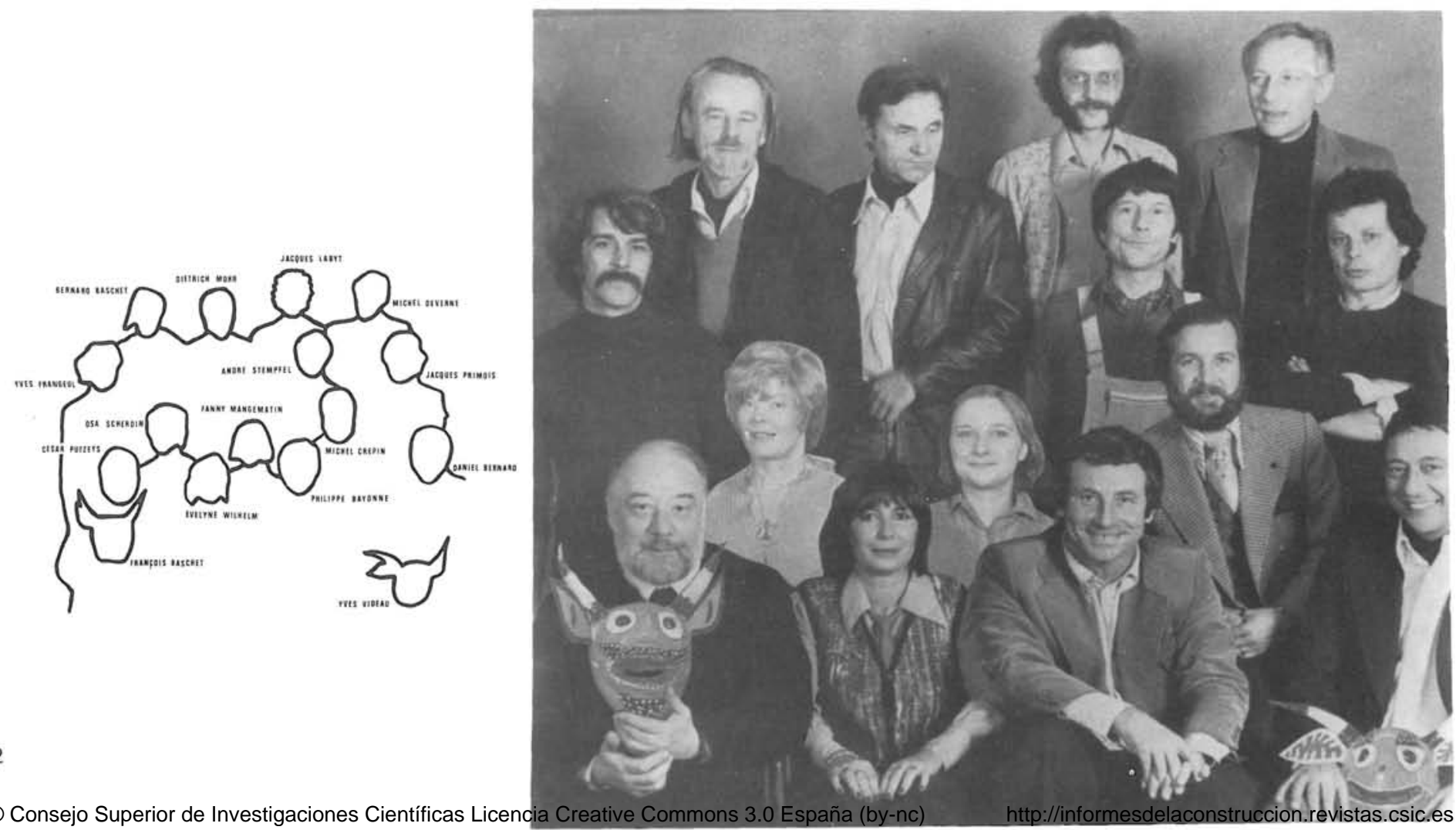


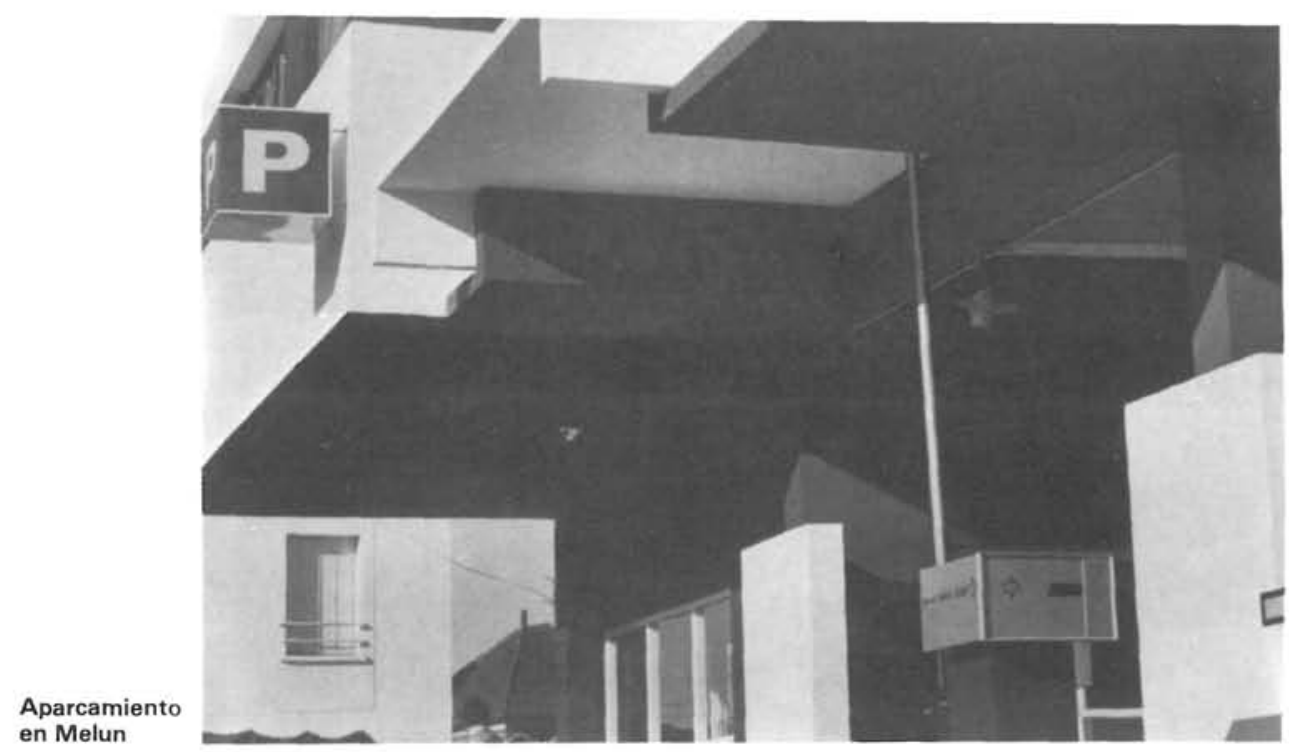

Las obras realizadas por Osa Scherdin para el T.E.S. de 600 alumnos en Faremoutiers, el fresco del C.E.S. de 996 alumnos en Montereau Fault Yonne cuyo autor es Yves Videau, las esculturas de Michel Deverne en el Ayuntamiento de Avon, el albergue de juventud de Chauny y los T.E.S. de 996 alumnos en Esbly, los frescos de Fanny Mangematin para la escuela maternal Calle del Caporal Peugeot, en París, distrito 17, son muestra de la primera categoria de esta intervención. Las arañas del escultor César Puzeys, que adornan las oficinas técnicas de la azucarera Arcis Sur Aube, iniciativa muy rara entre las empresas privadas, así como el albergue para la juventud de Chauny, el pabellón de Actividades Culturales de Champagne Sur Seine y las diferentes salas de juego del polideportivo Léo Lagrange, en esta misma villa; las escuelas maternales de Avon y de Rubelles o el gimnasio de Avon son un ejemplo del tercer punto antes indicado, así como los móviles creados por los hermanos Baschet, escultores músicos.

Por último el amueblamiento propuesto por el dibujante Daniel Bernard se concibió siempre desde los primeros estudios.

Es necesario hacer figurar en esta lista de colaboradores los nombres de los fotógrafos Michel Crepin y Jacques Primois que nos dan a conocer todas estas construcciones. Además hay que añadir que este último ha colaborado en la puesta en obra del muro de figuras luminosas realizadas en la fachada del pabellón Pablo Picasso en Champagne sur Seine.

¿Cuál es la personalidad de cada uno de los que han intervenido y cuyos trabajos constituyen una muestra representativa de las investigaciones que se imponen actualmente en Francia, asi como en todos los paises industrializados y la toma de conciencia y el reconocimiento de una necesidad cultural inscrita en el urbanismo?

\section{Philippe Bayonne}

Philippe Bayonne, nacido en 1932, arquitecto D.E.L.G. de Paris, laureado por el Instituto, uno de los 150 arquitectos que componen el Círculo de Estudios Arquitecturales, experto de acuerdo con el Gobierno Brasileño para la elaboración del esquema director del acondicionamiento turistico de $4.000 \mathrm{~km}$ del litoral nordeste de ese pais y que ha consagrado principalmente su actividad a las colectividades públicas y locales en Francia.

Su obra va dirigida principalmente a establecimientos escolares del primer y segundo ciclo, asi como a realizaciones culturales y conjuntos deportivos.

Ha realizado en Champagne-Sur-Seine, a $70 \mathrm{~km}$ de Paris, uno de los primeros conjuntos integrados, es decir, un conjunto de edificios que agrupan actividades tradicionalmente distintas y separadas, pero teniendo una finalidad común, en este caso la de acoger el público y su implantación en el bosque de Fontainebleau, lugar protegido y en las proximidades de su castillo de renombre mundial, una ciudad escolar técnica de 23.000 $\mathrm{m}^{2}$. cuyas características han tenido en cuenta las preocupaciones formuladas por los ecologistas y los defensores de la naturaleza.

Ha realizado igualmente, y de forma particular, en Arcis Sur Aube, un conjunto de oficinas cuyo aspecto se aleja mucho de la idea convencional conque se hacen este tipo de edificaciones. 


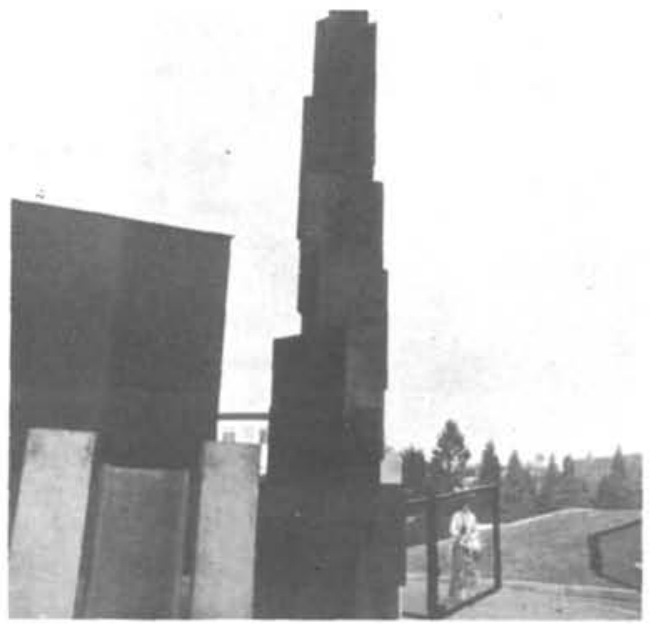

Escultura en el valle de Avon.

\section{André Stempiel}

Nacido en Francia en 1930, de padres suizos, se instala en París en 1957.

Pintor-escultor y gravador, sus obras están presentes en varios museos y colecciones del Centro Nacional de Arte Contemporáneo del Estado Francés y de la Villa de Paris.

Depurando sus formas al extremo, juega con un equilibrio-desequilibrio que desafía la lógica. Por medio de un vocabulario sobrio y puramente plástico, crea un clima misterioso propio de la meditación.

Se le debe una veintena de realizaciones monumentales, de gran envergadura, que se integran armoniosamente con la arquitectura aportándola en contrapunto una dimensión poética.

Estas realizaciones han sido creadas con los materiales más diversos y en función del entorno propuesto: acero esmaltado, mármol, hormigones policromados, piedra, hormigón lanzado...

$\mathrm{Ha}$ expuesto en los principales salones parisinos: Grands et Jueunes d'Aujourd'hui, Réalités Nouvelles, Comparaisons, Salón de Mayc y Biennale des arts de la Rue...

Su última exposición personal fue el 18 de abril del presente año en la galeria Rive Gauche de Paris.

$\mathrm{Ha}$ tenido el premio del Salón Internacional de Toulon, del Museo de Bayeux, y de pinturas y esculturas suizas en 1978 .

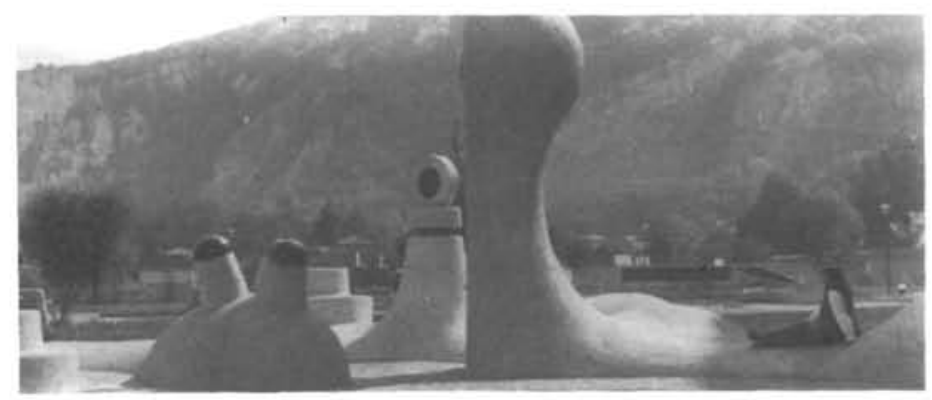

Conjunto escultural de hormigón lanzado con capa esmaltada, cerca de Grenoble.

\section{Yves Frangeul}

Nació en 1940, en Nantes, realizando sus estudios secundarios hasta 1957, año en que se matricula en Bellas Artes de esta ciudad hasta 1960. Se matricula de nuevo en Bellas Artes en Paris, en la sección pintura hasta 1964.

Ha colaborado en la realización de composiciones murales de Soto. Decorados, máscaras para el "Teatro del Movimiento", alternando con la ejecución de carteles para "Art Blackey".

Ha realizado trabajos de acondicionamientos y de arquitectura interior en la Casa de la Cultura de Paris.

Ha realizado también decorados y vestuarios para la "Cantatriche Chauve" en Nantes, en 1960.

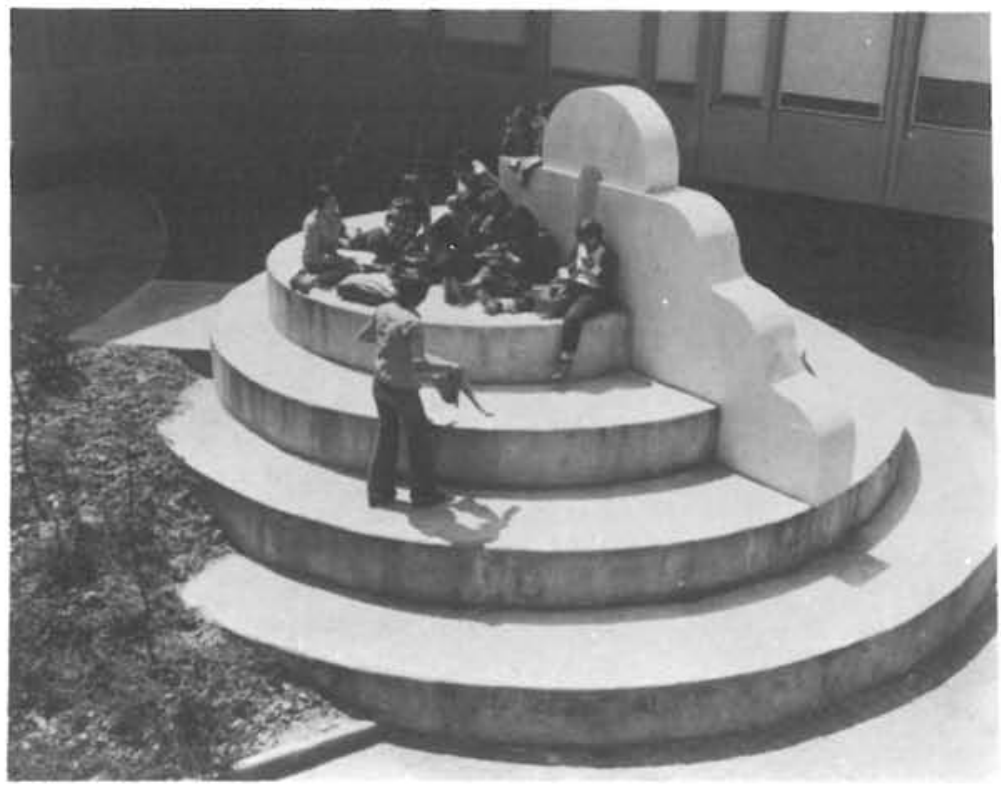

Escultura policromada en mármol de Carrara.

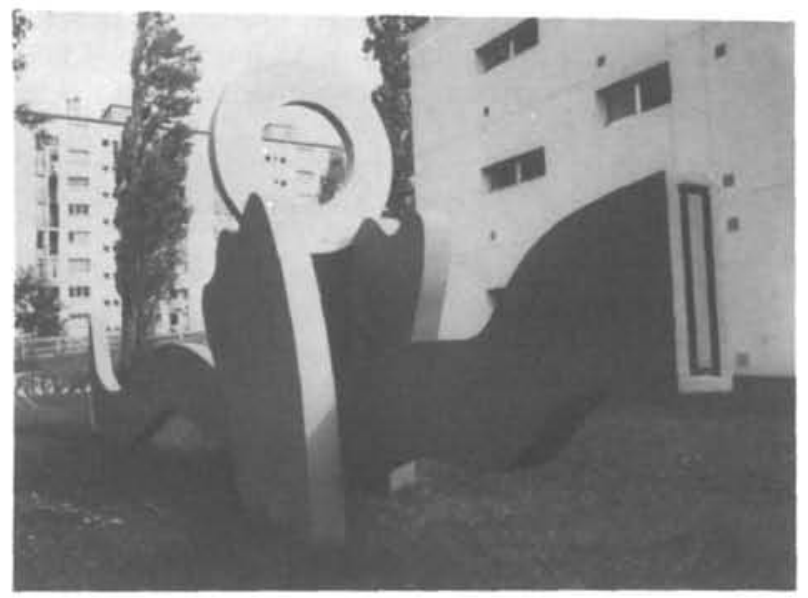

Escultura en hormigòn policromado. 


\section{Evelyne Wilhelm}

Asistente de su marido André Stempfel, está considerada como elemento literario que aporta una visión diferente a la de los plásticos y arquitectos.

Poeta y escritora nacida en Vichy pero viviendo en Paris desde su infancia. Desde muy joven frecuenta los medios artísticos y literarios parisinos y organiza desde la edad de 18 años reuniones poéticas con presentación de artistas.

Muy relacionada con las artes plásticas organiza numerosas exposiciones: pintura-poesia, y entre otras "la luz de la mano", en 1971. En 1972 hace la presentación de varios artistas: Dmitrienko, Giacometti, Gilioli, Kijno, Schneider, Soulages, Zack, Zaou woo ki... y entre poetas: Follain, Dansel, Guillevic, Jacottet, Labrusse...

Ediciones Larousse le han confiado la redacción de los capitulos dedicados al arte moderno (pintura, escultura, arquitectura) en la nueva y pequeña edición aparecida en 1977.

Colabora activamente con su marido en la realización de numerosas esculturas monumentales y, además, forma parte del grupo artístico que agrupa regularmente el arquitecto Fhilippe Bayonne.

\section{Dietrich Mohr}

Nacido en Alemania, en 1924, ha trabajado en Paris.

Después de haber estudiado Bellas Artes en Karlsruhe y en otros centros similares de París, donde aprendió a modelar en barro y esculpir en piedra y madera, dedicó especial interés al metal, en el cual ha estado trabajando exclusivamente los últimos 20 años. Sus preferencias se orientan hacia el bronce, el acero inoxidable y el acero cor-ten. Con un profundo conocimiento y sentido de las caracteristicas especiales de estos metales - su ligereza de peso y de espesores, en relación con su enorme resistencia y las cualidades refractarias del bronce y del acero inoxidable- Mohr ha alcanzado un notable éxito en la creación de todo un mundo de esculturas metálicas en las que se aprecia un original desarrollo del interior asi como del espacio exterior.

El equilibrio armonioso de las formas abiertas y cerradas, revela un conocimiento profundo de la arquitectura. La composición de espacios abiertos, base de planos y concavidades, permite la penetración de la luz en los interiores, creando asi un poético diálogo entre luces y sombras - siempre diferentes y cambiantes - que depende de la luz misma y del ángulo en el que está situado el observador.

Durante muchos años Dietrich Mohr ha participado en todas las exposiciones importantes de Paris, asi como otras montadas en el extranjero. Después de 3 exposiciones individuales, el Gobierno francés le organizó una exhibición ambulante, por la mayoria de los museos del pais, asi como en diversas instituciones culturales, durante los años 1977 y 1978. Tambièn se han previsto otras exposiciones personales para los años 1979 y 1980.

Además de todo esto, Mohr ha sido encargado de realizar 20 esculturas monumentales destinadas a escuelas, colegios y plazas públicas,

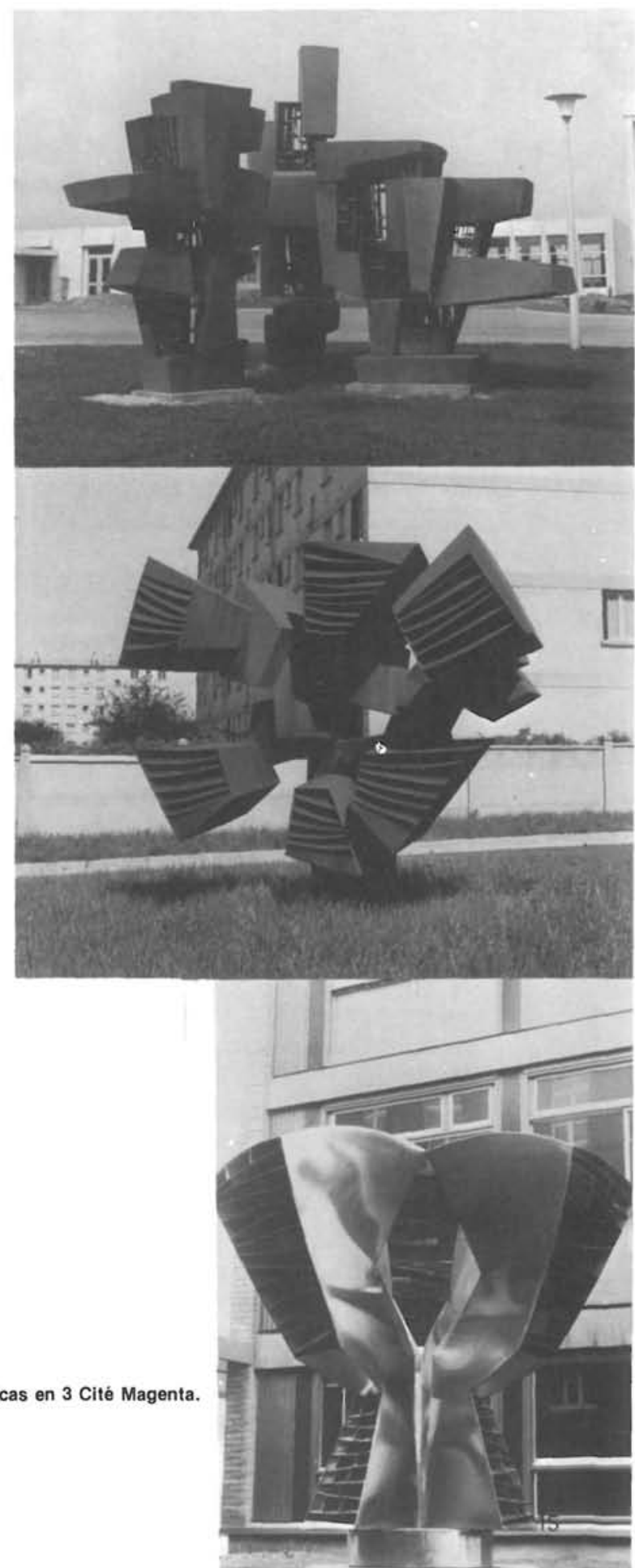


Nacido en Francia, 1936, y asistente durante cuatro años a los estudios fotográficos de Elle en Paris.

Fotógrafo independiente desde 1962 dedicado especialmente a la fotografia de decoración y publicidad. Colabora en las revistas "La Maison de Marie Claire», de París, "Arkitektur et Wohnen", de Hamburgo y "Architectural Digest" de U.S.A. realizando igualmente tomas publicitarias para sociedades como: Formes Nouvelles de Paris, Habitat de Londres y Knoll International.

Aunque muy especializado en la fotografia de interiores ha realizado reportajes de gran interés en los conjuntos arquitectónicos de Fhilippe Bayonne, en razón a la gran libertad que éste le ha autorizado con resultados importantes.

Este clima de trabajo le parece bastante raro para ser subrayado, ya que muchos arquitectos y decoradores están demasiado atados, desde su punto de vista, a un fotógrafo "neutro" de sus obras.
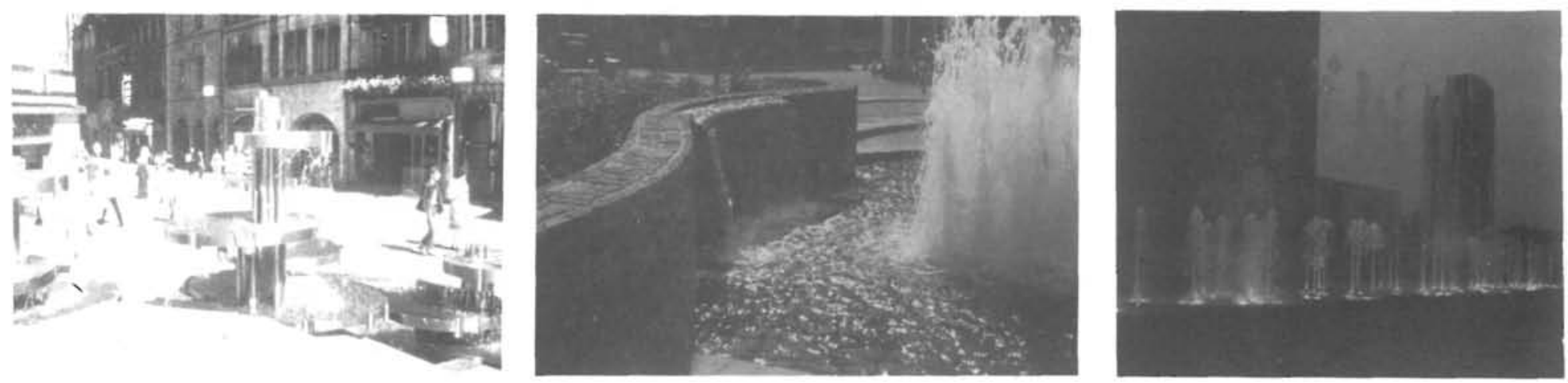

\section{Deverne (Galerie Reflets)}

La integración de las artes, defendida e ilustrada generosamente por el llorado André Bloc, hace ya más de 20 años, empieza a encontrar algunos realizadores de valía.

Es asi como en la Galeria de Simone Eymonet, Deverne, del cual habiamos visto hace tiempo algunos proyectos, esencialmente dibujados y acuarelados, nos vuelve este año con piezas cuya elocuencia, fuerza y densidad deben llamar la atención de los aficionados y, sobre todo, el interés de los arquitectos a los cuales están, sobre todo, destinadas.

Sensible al arte constructivo de Julio Le Parc y de Demarco, tan arbitrariamente expulsados estos últimos días de un país que supieron tan generosamente honrar, los trabajos de Deverne no se entienden, sin embargo, conjuntados a una opción cinética.

El movimiento, para este artista, al contrario de Julio Le Parc, no está creado o sugerido por algún desplazamiento del observador o por el mecanismo de la composición.

Si cierta movilidad se impone, en sus paneles, es a las fluctuaciones del astro-rey, jugando sobre las piezas metálicas del conjunto, a lo que se debe esta animación virtual.

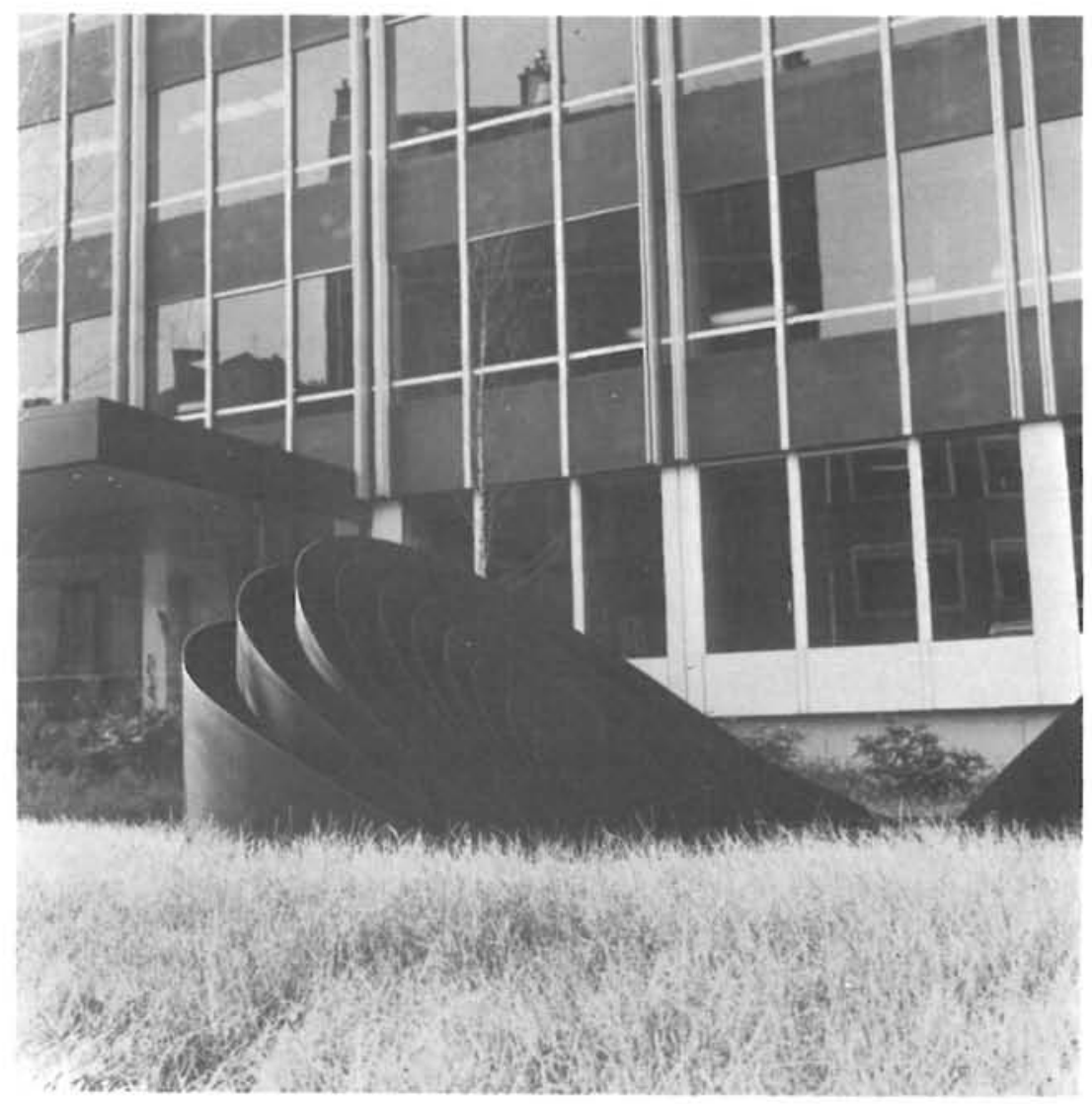


Osa la invención plástica es ligada a la emoción tan estrechamente que el título que debe designar la obra surge por si mismo, con la nitidez de un poema exactamente apropiado. , Michel Conil Lacoste

Reconozco que mis relaciones con la tierra son muy especiales, es en efecto una materia de preferencia.

La tierra posee una plasticidad que no puede ser reemplazada por ninguna otra materia. Pasa ¿después de cuántas aventureras formales? del muy suave, hasta el liquido, hasta el duro y, una vez cocida, el muy duro - por cierto Bachelard me habria comprendido-. Pienso en este bello poema, en prosa, su ensayo "La tierra o el Ensueño de la voluntadn.

Abrir una esfera, separar sus paredes secretas, conocer el interior de las cosas y sus comportamientos, una parte para la dulzura, otra parte para la violencia... el día y la noche, un pasado o un acto más que una imagen propiamente dicha... esto y aquello, lo positivo de un acto y su lado negativo, cómo no estar fascinado por la imagen y su doble, la simetría me apasiona y cuál será el diálogo entre los dos...

¿Poner derechas dos varillas? ¿Qué pasa? Las dos varillas se aproximan la una a la otra por el magnetismo innato de los cuerpos; el más fuerte gana, el más débil se inclina y se apoya. Infinitamente lógico lo que pasa, aqui estoy en espectadora atenta y paro el acuerdo que se hace entre los dos volúmenes en el momento útil, confirmo con un enlazamiento doble este entendimiento y dejo al horno el cuidado de darle la prueba del fuego.

(A propósito de los "Amantes admirables») Osa Scherdin
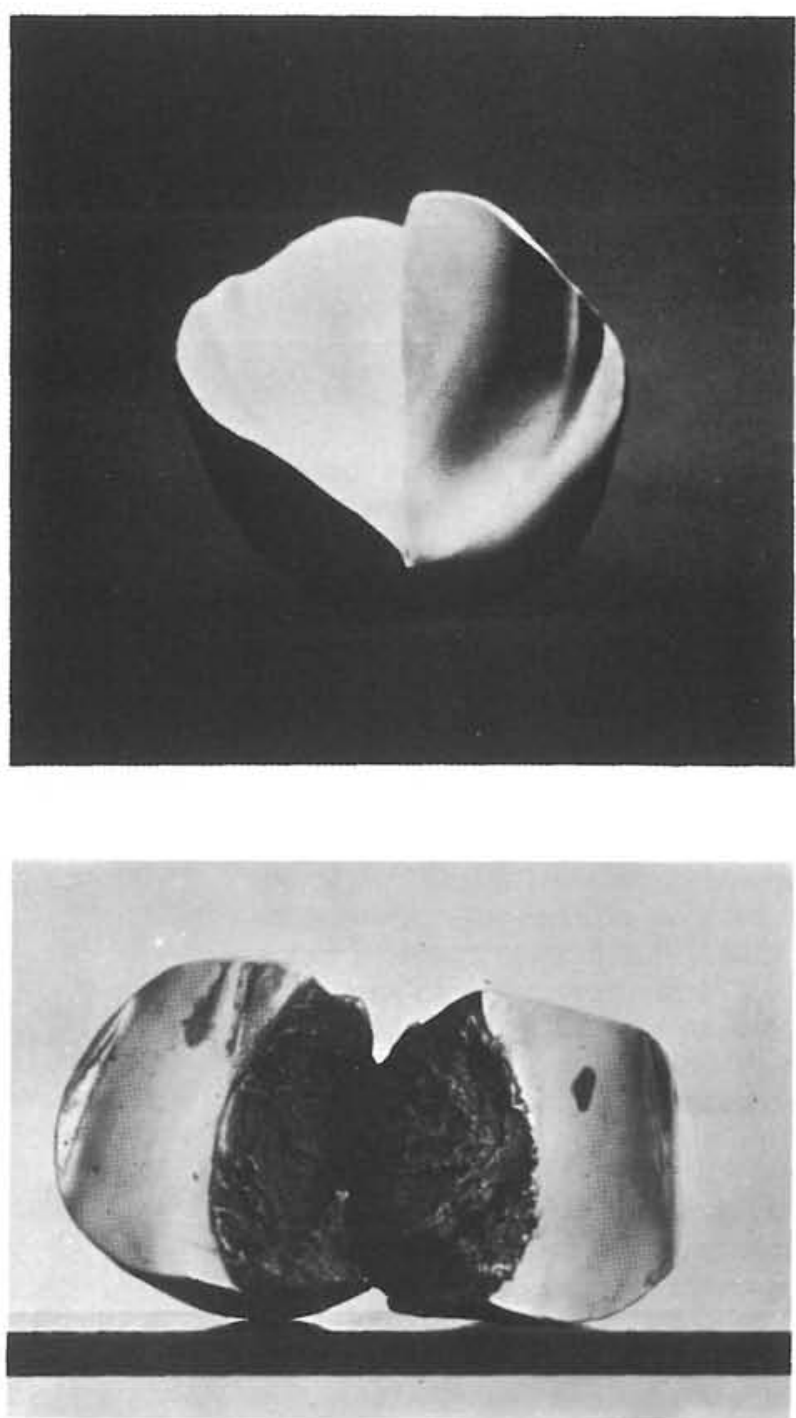

\section{Fanny Mangematin}

El 3 de mayo de 1946, la nieta de un dibujante humorista parisino e hija de un borgoñés de larga tradición, nace bajo el signo de la alegria.

Comparte su infancia entre la escuela, donde colecciona más amigos que buenas notas, y las vacaciones en Borgoña donde se impregna, en el feliz medio familiar, de la armonia sin el amaneramiento del paisaje.

Es esta salud y esta alegria lo que buscará expresar y transmitir más tarde.

Después de sus estudios en Bellas Artes, sección pintura, y en la Escuela Martenot, enseña este método de dibujo en un estudio de niños y en cursos particulares para niños dificiles.

Es en 1970 cuando realiza su primera exposición de pintura en Cruny.

Apasionada por los paisajes sigue durante dos años cursos de la Escuela Especial de Arquitectura de jardines y trabaja hasta 1976 con arquitectos paisajistas.

En 1976, por presión del arquitecto Bayonne realiza dentro del cuadro del 1 por 100 un proyecto de mural en una escuela maternal bajo la forma original de un puzzle gigante imantado, lleno de frescor.

Posteriormente, y siempre estudiando proyectos de jardines o paneles decorativos para diversas municipalidades de Saône y Loire, trabaja la pintura en vista a una futura exposición. 
Los elementos de luminosidad puestos a punto por César Putzeys, desde 1962, se presentan como el fruto de investigaciones minuciosas cuyos pasos, todos, están articulados alrededor de una misma preocupación: la satisfacción estética, que puede extraer un espectador de su uso y de su contemplación. Lo logran gracias a una serie sutil de triunfos: luz repartida de una manera uniforme, sin herir la vista, objeto adaptado por su forma general, cada uno de sus elementos constitutivos, el material escogido (aluminio) con el cuidado de ser eficaz y de conseguir una belleza equilibrada y discreta aunque el elemento de luminosidad esté sin funcionar.
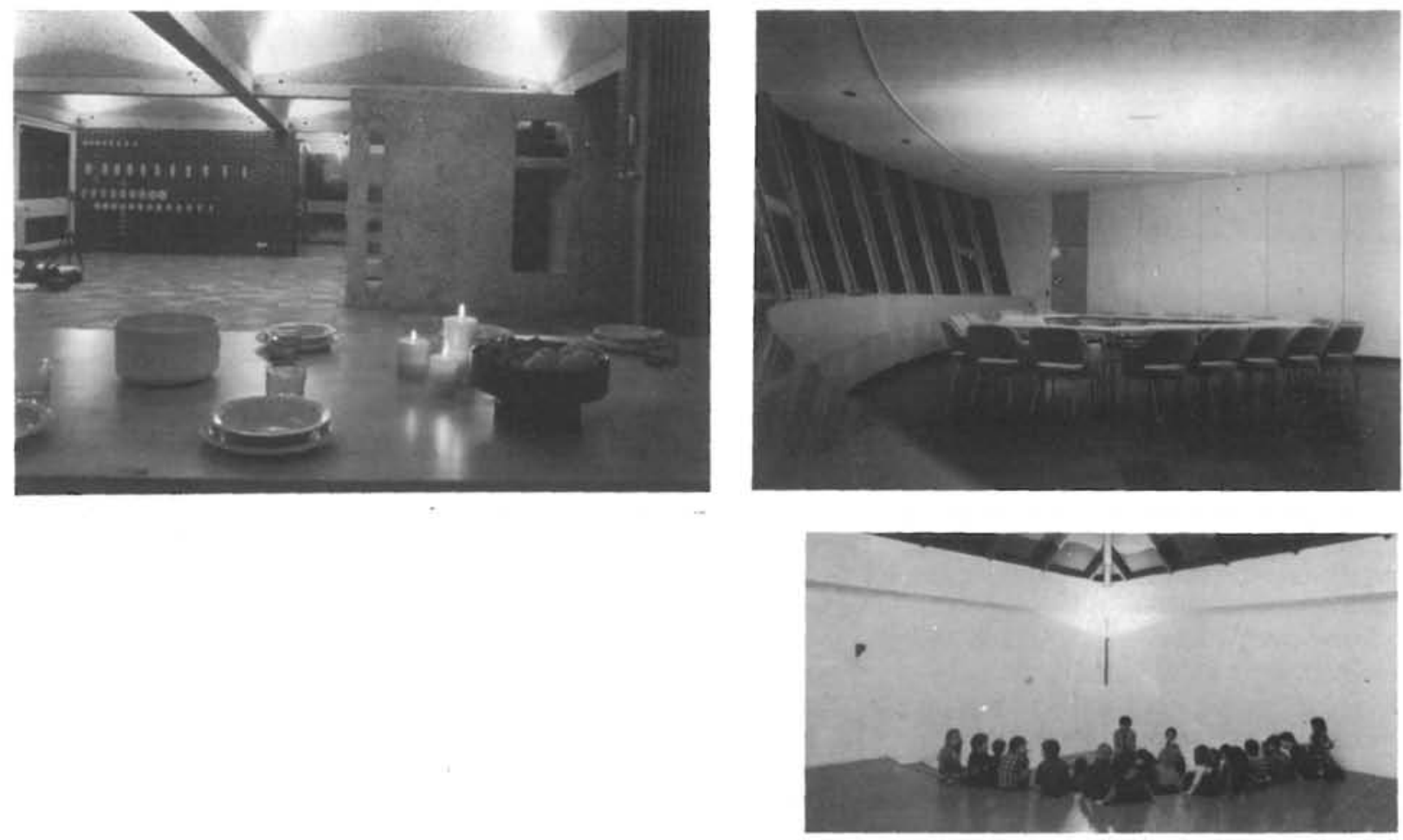

Un objeto de esta calidad es como una idea enunciada en un lenguaje preciso cuya genialidad no está contrariada por ningún componente del discurso y con una gran preocupación de economía de los medios puestos en acción. En un caso de este género aparece como indiscutible que las cualidades estéticas surgen de la sola (y muy poco común) limpidez. Pero lo que puede parecer muy simple cuando todo lo supérfluo ha sido borrado, es el resultado de pacientes puestas a punto. Los modelos sucesivos que precedieron los expuestos ahora por César Putzeys muestran con elocuencia la preocupación de perfeccionamiento y el largo camino recorrido para encerrar una idea rigurosa.

Es el conjunto de estas preocupaciones asociadas a sus virtudes que valieron a César Putzeys llevarse el "Signe d'Or" la más alta distinción acordada en Bélgica para este género de creación y atribuida por primera vez a un elemento de luminosidad.

Las preocupaciones estéticas son también confirmadas por la perfecta unidad de estilo entre los aparatos de luminosidad y los apliques murales creados por el mismo autor.

Que César Putzeys sea un renovador aparece muy claramente si se refiere a los productos propuestos sobre el mercado antes de entrar en escena. Los primeros modelos que presentó, como es generalmente el caso para todo lo que es realmente nuevo, asustaron algunos clientes potenciales sorprendidos por esta simplicidad rigurosa que no encontraban en esos objetos una cierta concepción del lujo en uso entonces.

Al igual que se puede proceder para la obra de grandes creadores en pintura y escultura, es interesante seguir desde los primeros modelos nacidos en 1962 la constancia de un mismo caminar. Así, aun al estado de descanso o de no funcionamiento, el haz de aluminio, animado de reflejos muy puros despierta aún la idea de luz. Ningún detalle ha sido dejado al azar, ni la terminación abrupta adoptada actualmente para el elemento horizontal, ni tampoco la relación entre su alcance y la longitud de los elementos verticales de sustentación, ni el volumen de unos y otros. Estos elementos de sustentación el autor los ha querido discretos y ligeros, pero no ha buscado disimularlos, como hubiera podido hacelo, utilizando materiales trasparentes. Por el contrario, en algunas aplicaciones de gran vuelo, ha escogido suprimirlos radicalmente anclando los extremos del haz horizontal en la pared. 


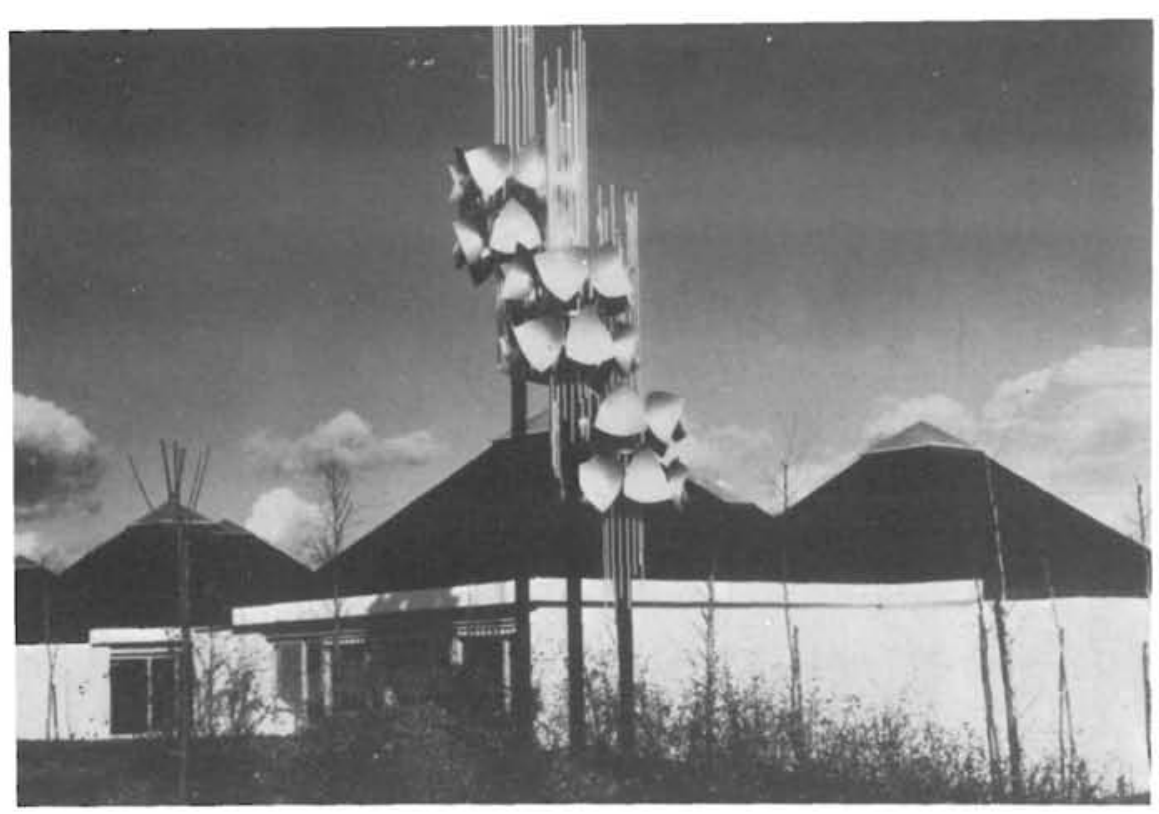

FOTO: P. JOLY - V. CARDOT

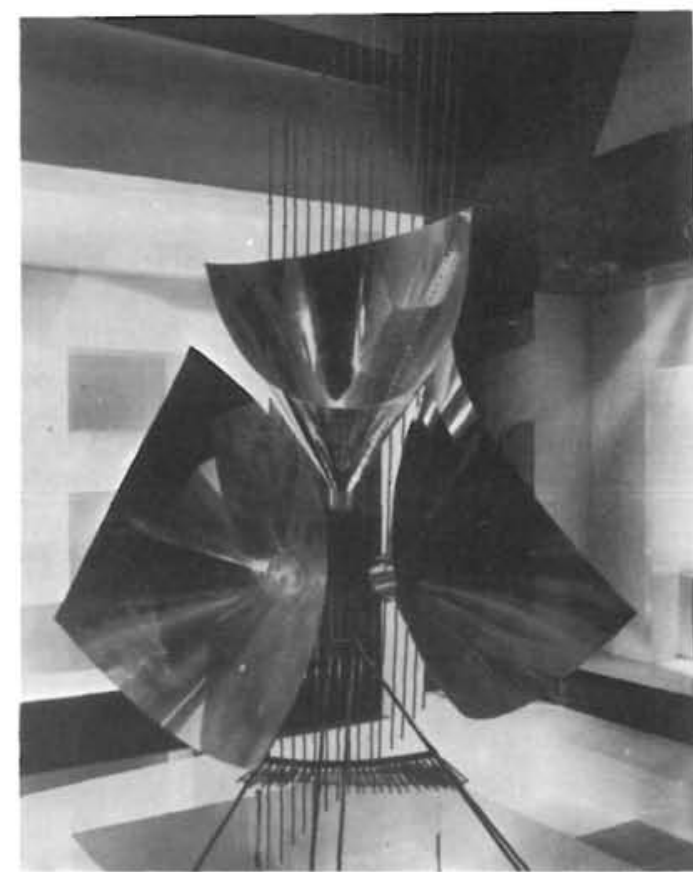

Se puede sacar de todo esto la conclusión que el modelo que valió el Signe d'Or le sirve ahora de elemento de base susceptible de conocer variaciones según los programas que le son propuestos. Asi se ha constituido un vocabulario a partir del cual puede permitirse componer obras diferentes. Los elementos de luminosidad - esculturas de César Putzeys - corresponden a un estado de espiritu y a una línea de conducta que le son propios.-Al igual que para las obras pictóricas o esculturales se podría fácilmente crear una ilusión copiando las características más superficiales, pero no la elocuencia profunda de los modelos. Para referirnos a un ejemplo ilustre diremos que Vasarely no es ciertamente el primer hombre que ha dibujado un círculo dentro de un cuadrado. Sin embargo, es el primero en haber desarrollado esta asociación de formas hasta extraer un lenguaje. Utilizar asociaciones de círculos y de cuadrados para engendrar una ilusión de modernidad apareceria ahora como un acto poco grato y deshonesto. La única excusa consistiría en volver a partir del elemento de base para sacar un lenguaje totalmente diferente. Pero la tentativa, es verdad, nos pareceria estar condenada al fracaso. Lo que es verdad de las caracteristicas que constituyen la obra de Vasarely lo es igualmente de los componentes que animan los elementos luminosos de César Putzeys. Negarlo equivaldría negar las cualidades estéticas de estas obras, y no vemos, realmente, sobre qué bases se podria establecer semejante demostración.

Selim Sasson

\section{Hermanos Baschet}

Los hermanos, François y Bernard, crean y realizan "esculturas musicales" que han sido expuestas en diversos museos, entre ellos el de Arte Moderno de Nueva York.

Ambos artistas son partidarios de llevar el arte y concretamente la escultura moderna, al alcance del "pueblo", a fin de que pueda sentirla, admirarla, estudiarla y comprenderla.

François y Bernard Baschet han roto con las barreras tradicionales entre el sonido y las formas plásticas.

François empezó siendo un escultor tradicional trabajando junto a Yencesse, en los años 50, y más tarde al lado de Auricoste, de tendencias más modernas, aprendiendo con ellos las dificultades ténicas del grabado y el modelado.

Bernard es ingeniero, especializado en acústica.

Ambos hermanos se unieron en 1953 y desde 1955 han desarrollado una técnica especialísima a base de formas metálicas o de cristal que, al vibrar, producen sonidos armoniosos que nos recuerdan a los órganos románticos.

En la exposición de Colonia de 1971 organizaron un concierto con el compositor alemán Henkemeyer, a base de los instrumentos especiales de los hermanos Baschet. 
Japón es otro campo en el que han obtenido extraordicarios éxitos las obras de los hermanos Baschet, interiniendo en la Expo 70 de Osaka -invitados por la =ederación Japonesa del Acero- colaborando con zompositores como Temikazu.
François ha fijado su residencia en España, pero los dos hermanos han recorrido prácticamente todo el mundo y sus obras se exponen en los museos de Nueva York, Suiza, Bélgica, Alemania, etcétera.

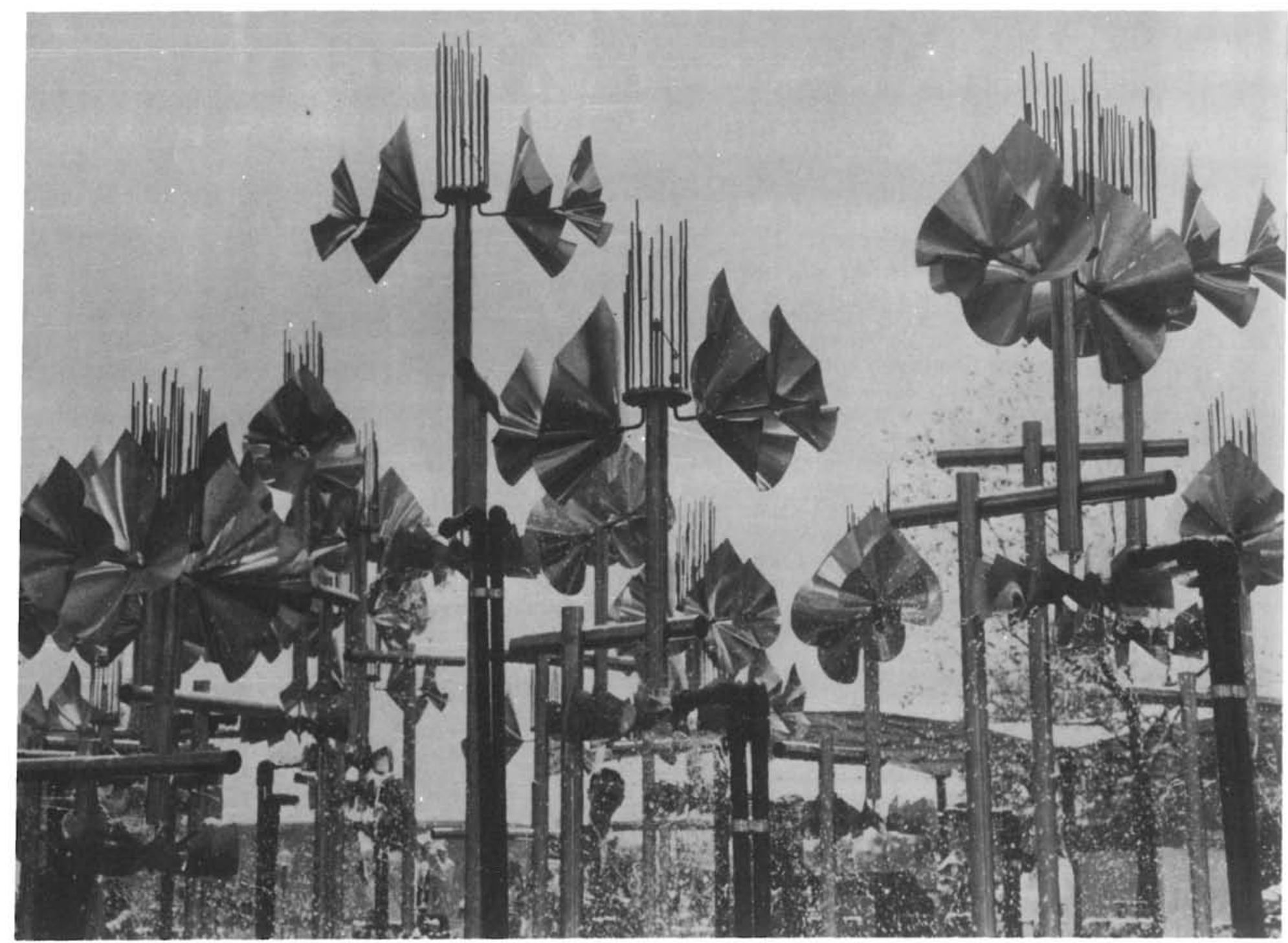

Puente en San Antonio de Texas.

\section{Daniel Bernard}

Nació en 1929 en Paris donde ejerce actualmente.

Después de sus estudios secundarios entra en la Escuela Nacional Superior de Bellas Artes de París, Sección Arquitectura, quedando inscrito hasta 1952.

Interesado por la arquitectura de interior y, particularmente, por el mobiliario contemporáneo, Daniel Bernard efectúa diferentes cursillos de formación en esta rama: Oficina de Arquitectura de Interior de la U.S. Army Quater del Camp des Loges en St. Germain en Layes; Sección Decoración para un gran almacén de Paris, y después en Niza. Trabajos en colaboración con diferentes arquitectos antes de entrar en la Sociedad Airborne como animador de la Oficina de Estudios y de Creación, y después como director técnico.

Bajo su impulso, esta Sociedad desarrollará sus procedimientos de prefabricación inéditos, tales como las estructuras de chapa de acero delgado en poliuretano rigido, el sobremoldeado de espuma flexible sobre armaduras metálicas, la inyección de espumas flexibles directamente en las guarniciones de asientos. Es, en parte, gracias a estas técnicas de vanguardia, aplicadas a la fabricación de asientos contemporáneos, que la Sociedad Airborne llegará a un nivel internacional permitiéndole editar, bajo licencia, sus modelos en el mundo entero: Canadá, Japón, Colombia, Australia. 

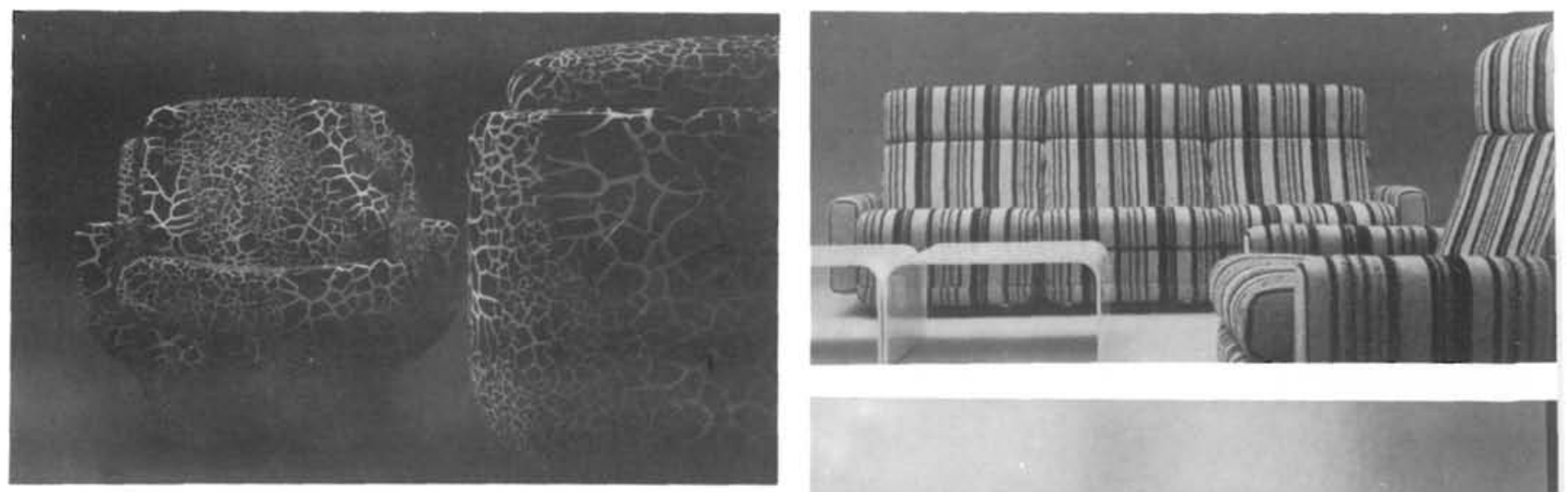

Además de sus creaciones personales, que tendrá la oportunidad de presentar en los Salones de los Artistas Decoradores en Paris, 1958 y 1960, y la realización de modelos especiales para la ejecución de grandes obras tales como el transatlántico France (comedor), el auditorio del Museo de Artes y Tradiciones Populares, las salas de espera de los Aeropuertos de Orly Sur y Orly Oeste, Daniel Bernard se dedica, sobre todo, al desarrollo del dibujo contemporáneo y favorece la promoción de creadores a los cuales aporta su apoyo y sus conocimientos técnicos para la puesta a punto de sus modelos. Es asi que los modelos Joker, Djinn y Whist d'Olivier Mourgue, el modelo Half and Half de Christian Germanaz, el modelo Delta de Etienne Fermigier, el modelo Albatros de Danièle Quarante y la serie 3000 de l'Abaque, serán editados y realizados bajo su impulso por la Oficina de Estudios de S. A. Airborne.

Desde 1976 Daniel Bernard está asociado con Dominique Saint Guilhem, para constituir su propia Oficina de Estudios e Investigación, para la creación de mobiliario contemporáneo. Esta Oficina de Estudios, $D+D$, ha creado ya varias colecciones de asientos cuya realización ha sido confiada a industriales de España, Francia y Japón.

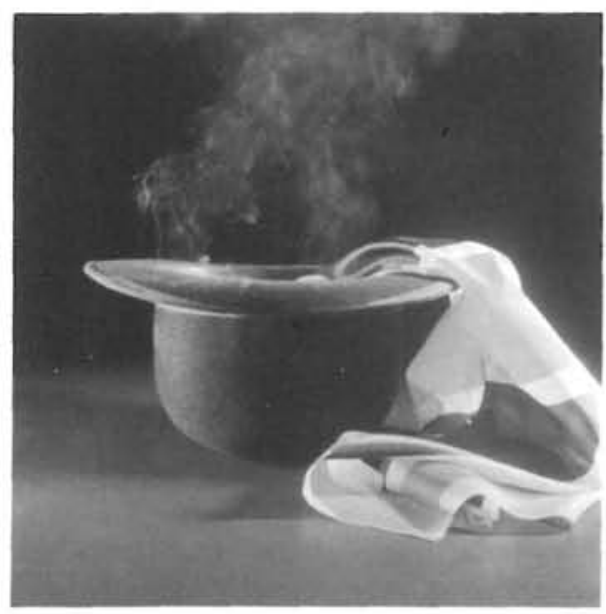

\section{Michel Crépin}

Nacido en 1938, en el Norte de Francia, en BoulogneSur-Mer.

Comienza a trabajar en Paris en 1958 después de realizar estudios artisticos en la Escuela de Bellas Artes de Amiens, siendo su pasión la fotografia.

En París encuentra numerosos reporteros fotográficos de varios periódicos.

Introducido muy temprano en el mundo del periodismo, ya que su padre es a su vez periodista, debuta con reportajes deportivos y de sucesos.

Sus investigaciones le llevan, en principio, hacia la moda. Después se orienta en fotografía publicitaria insólita; aunque hoy en día le tienta la fotografía ficción que corresponde más a sus profundas aspiraciones.

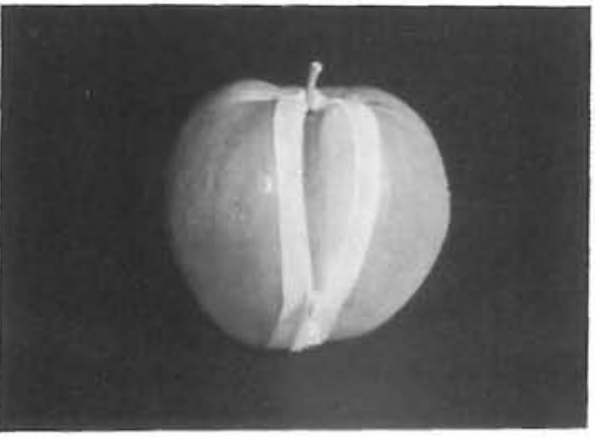



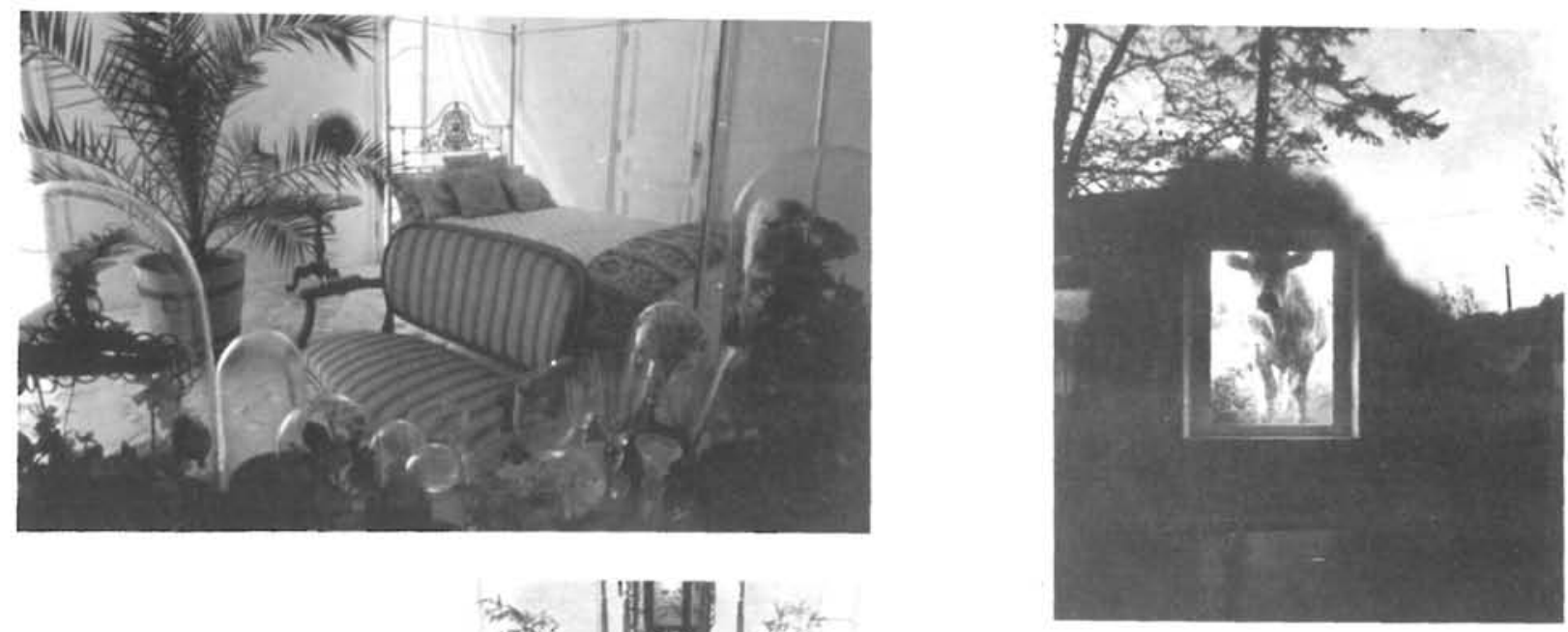

\section{Jacques Labyt}
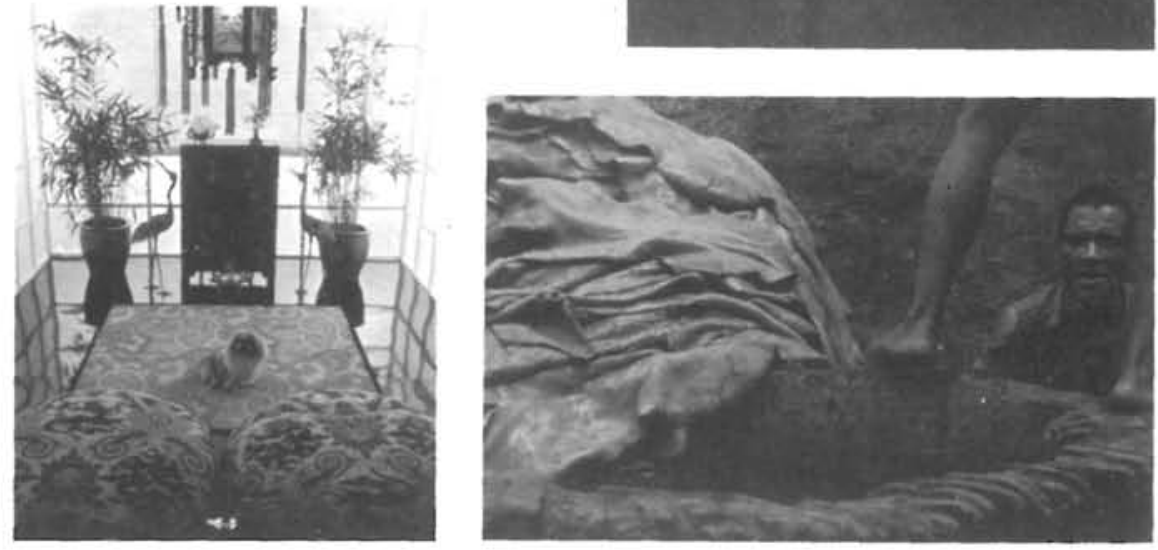

Tiene una pasión, el agua.

Nacido en Saint Denis, en 1941. Después de los estudios que le abrieron los caminos habituales en este mundo, ha descubierto las posibilidades que le daba el agua.

El agua, naturalmente en movimiento, origen de la vida y de la reflexión, apaciguadora o estimulante y dominada por la sensibilidad y la imaginación.

Este camino asi abierto, es con comprensión que integra armoniosamente obras de agua en el urbanismo actual.

Algunas veces aéreas, les hace abrirse y proyectarse así hacia el exterior, o cerrarse y acurrucarse en tantas formas que, aliadas a la luz, irradian por si una explosión de vida.

Algunas veces, misteriosas, hace surgir la masa liquida pacífica y tranquila que camina y desaparece.

Otras veces desgarrando un poder contenido que entonces brota con un géiser, y en fin, cuantas sensaciones el hombre siente y desea expresar en nuestra vida moderna.

Numerosas exposiciones internacionales han hecho eco de su trabajo y cree que deberia ser un hecho más frecuente contemplar el agua en las ciudades y en la vida.

\section{résumé}

LES OEUVRES D'ART EN ARCHITECTURE, $1 \%$

Philippe Bayonne, architecte

Nombreuses sont les oeuvres d'art dues à l'heureuse idèe du Ministère de l'Education, de consacrer un crédit de un 1 por 100 sur le coût de la construction, pour realiser des décorations monumentales intégrées à tous les édifices scolaires et universitaires de l'Etat.

On pourrait résumer en trois les fins de projet:

- aider les artistes à vivre de leurs oeuvres:

- mettre l'individu en contact avec l'art dès le plus jeune age:

- intégrer les arts dans l'architecture.

Les résultats obtenus ont étè si encourageants que, par la suite, d'autres ministère et même quelques municipalités ont contribué, en quelque façon, au développement de cette idee.

Philippe Bayonne a intervenu fréquemmen en ces types de réalisations. Lui, son oeuvre et ses collaborateurs sont présentés ici.

\section{summary}

$1 \%$ FOR ART IN ARCHITECTURAL
WORK

Philippe Bayonne, architect

There have been many works of art created thanks to the felicitous idea of the Ministry of Education by which 1 per 100 of all public moneys allocated for the construction costs of school or university buildings is earmarked to pay for large-size ornamental works of art.

The purpose of this project can be summarised en three points:

- Help artists to make a living from their work.

- Establish contact between art and the people from the citizens' early years.

- Integrate art and architecture.

The results are so encouraging that other Ministries and even some municipalities have followed and contributed one way or the to expand the idea.

Philipe Bayonne has often participated in these projects. His work, and that of his collaborators, is presented in this article.

\section{zusammenfassung} KUNSTWERKE IN DER ARCHITEKTUR, $1 \%$

Philippe Bayonne, architekt

Zahlreiche Kunstwerke verdanken it, Bestehen der glücklichen Idee des Ministeriums für Erziehung, einen Kredit von 1 pro 100 der Baukosten zu gewähren, damit alle vom Staat finanzierten Schul- und Universitätsgebäude in denkmalähnlicher Weise dekoriert werden.

Die drei Ziele dieses Projektes könnten wie folgt zusammengefasst werden:

- Den Künstlern zu helfen, von ihrem Werk zu leben;

- Den Menschen von den jüngsten Jahren an mit der Kunst in Kontakt zu bringen und:

- die Künste mit in die Architektur einzubeziehen.

Die erzielten Ergebnisse waren so erfreulich, dass später auch andere Ministerien, und sogar einige Stadtgemeinden, in irgendeiner Weise zur Entwicklung dieser Idee beigetragen haben.

Philippe Bayonne war häufig an solchen Bauausführungen beteiligt. Mit seinem Werk und seinen Mitarbeitern hat er sich bei dieser Arbeit einen Platz errugen. 